\title{
Alinhamento interfuncional: um estudo exploratório sobre os pontos de contato entre marketing, logística e produção
}

\section{Cross-functional alignment: an exploratory study on the points of contact among marketing, logistics, and production}

\author{
Andrea Lago da Silva ${ }^{1}$ \\ Guilherme Hernandes Vasconcellos Lombardi ${ }^{1}$ \\ Márcio Lopes Pimenta ${ }^{2}$
}

\begin{abstract}
Resumo: A integração interfuncional das atividades de Marketing, Logística e Produção é essencial para a coordenação entre demanda e suprimentos e o alinhamento integração interfuncional é um passo importante nessa direção. $\mathrm{O}$ objetivo deste trabalho é identificar os principais pontos de contato entre Marketing, Logística e Produção. Partindo de uma revisão de literatura, foi elaborado um roteiro semiestruturado e foram realizadas 19 entrevistas em uma indústria de bebidas. A partir da transcrição e da análise de conteúdo, foram caracterizados diversos pontos de contato entre as díades formadas pelas três funções e, diretamente, apenas um ponto de contato entre a tríade - o Lançamento de Produto. Entretanto, observou-se que, indiretamente, os entrevistados mencionavam outros pontos de contato que demandavam a contribuição de uma terceira função, como: previsão da demanda; promoção; transporte (entrega); nível de serviço; planejamento e sequenciamento da produção; planejamento da capacidade logística; e embalagens. Dentre as contribuições do artigo, destacam-se o aprofundamento da compreensão sobre o alinhamento interfuncional entre as três funções no nível tático e operacional e a sua contribuição para o alcance dos objetivos organizacionais mais amplos, como o nível de serviço oferecido aos clientes.
\end{abstract}

Palavras-chave: Integração interfuncional. Pontos de contato. Marketing. Logística. Produção.

\begin{abstract}
The cross-functional integration among Marketing, Logistics, and Production activities is essential for the coordination of demand and supply, and the interfunctional alignment represents an important step towards achieving it. The objective of this paper is to identify the main points of contact among Marketing, Logistics, and Production. Based on a literature review, a semi-structured guide was used for conducting 19 interviews in a beverage company. Based on the content analysis of the transcripts, many points of contact were found between the dyads formed by the three functions, and only one was found within the triad-the Product Launch. However, it was observed that the respondents indirectly mentioned other points of contact that required the assistance of a third function such as forecasting, promotion, transportation (delivery), service level, production planning/scheduling, logistics capacity planning, and packaging. Among the contributions of this article, it is possible to highlight the deeper understanding of the cross-functional alignment among the three functions at the tactical and operational level and their contribution to the achievement of broader organizational goals, such as the service level offered to customers.
\end{abstract}

Keywords: Cross-functional integration. Points of contact. Marketing. Logistics. Production.

\section{Introdução}

Nos dias atuais, a crescente complexidade do ambiente concorrencial tem exigido das empresas rapidez para tomada de decisão e uma sincronia cada vez maior entre demanda e suprimento. Marketing, Logística e Produção surgem como três importantes funções quando se procura equilibrar a demanda com a oferta (SHAPIRO, 1977; KONIJNENDIJK,
1994; BALLOU, 2006; GIMENEZ, 2006; LYNCH; WHICKER, 2008; MENTZER; STANK; ESPER, 2008; JÜTTNER; CHRISTOPHER; GODSELL, 2010). Essas três funções são reconhecidas na literatura por expandirem seus domínios conceituais de atuação, ou seja, estabelecem pontos de contato no ambiente interno (com outras funções) e externo (com outros

\footnotetext{
Departamento de Engenharia de Produção, Universidade Federal de São Carlos - UFSCar, Rod. Washington Luís, Km 235, CP 676, CEP 13560-970, São Carlos, SP, Brasil, e-mails: deialago@ufscar.br; guilombardi88@ gmail.com

${ }^{2}$ Faculdade de Gestão e Negócios, Universidade Federal de Uberlândia - UFU, Av. João Naves de Ávila, 2121, sala 1F242, CEP 38400-902, Uberlândia, MG, Brasil, e-mail: pimenta@ fagen.ufu.br
}

Recebido em 16/1/2013 — Aceito em 3/6/2013

Suporte financeiro: FAPESP Processos Bolsas nº 2009/05160-0; 2011/01657-8 e Auxílio Pesquisa no 2011//06008-8. 
membros da cadeia de suprimentos). Além disso, as três funções podem ser consideradas como clientes e fornecedoras internas durante o processo de criação de valor ao cliente (PIERCY, 2007). Entretanto, em alguns trabalhos há menção de que muitas empresas falham ao se integrar com clientes e fornecedores devido à baixa integração interfuncional que obtém em seus próprios limites operacionais (BARRATT, 2004; FAWCETT; MAGNAN; McCARTER, 2008). Autores diversos (PAGELL, 2004; OLIVA; WATSON, 2011) destacam também que poucos estudos explicam de forma detalhada o alinhamento interfuncional no nível micro.

Pontos de contato consistem em atividades que demandam esforço conjunto por duas ou mais funções para serem executadas. Turkulainen e Ketokivi (2012) destacam que, para a realização dos processos organizacionais, diferentes tipos de conhecimento são necessários. Do ponto de vista teórico, há necessidade de se entender conceitualmente o papel de cada função, caracterizar a integração entre elas e identificar em quais situações há necessidade de integrá-las (ELLINGER, 2000; OLIVA; WATSON, 2011). Do ponto de vista empírico, a identificação dos principais pontos de contato das três funções pode representar um ponto de partida para a integração interfuncional e para o uso de processos gerenciais como Sales and Operations Planning ( $S \& O P$ ), que podem contribuir tanto para alinhamento interno quando para o alinhamento com clientes e fornecedores, especialmente quando os sistemas de informação interorganizações favorecem a integração da cadeia de suprimentos (THOMÉ et al., 2012).

O objetivo deste trabalho é identificar os principais pontos de contato entre Marketing, Logística e Produção de modo a aprofundar a compreensão sobre o alinhamento interfuncional entre as três funções e sua contribuição para o alcance dos objetivos organizacionais. Este artigo está organizado da seguinte forma: na seção dois, são identificados os pontos de contato sob a ótica da integração interfuncional entre Marketing, Logística e Produção, considerando as díades e a tríade formadas por elas; na seção três, são apresentados os procedimentos metodológicos; na seção quatro, se confrontam os principais pontos de contato identificados no estudo de caso com os da revisão de literatura, ressaltando semelhanças e diferenças; a seção cinco discute as principais conclusões, limitações e implicações gerenciais da pesquisa.

\section{Integração interfuncional e os pontos de contato}

Lawrence e Lorsch (1967) e Shapiro (1977) foram os primeiros a estudar as dificuldades de se trabalhar o alinhamento interfuncional. A partir de então, diversos outros estudos foram desenvolvidos considerando diferentes aspectos da integração interfuncional. Enquanto alguns trabalhos se propuseram a conceituar a integração interfuncional (KAHN, 1996; KAHN; MENTZER, 1996; MURPHY; POIST, 1996), outros focaram aspectos aprofundados sobre o funcionamento da integração (ELLINGER; KELLER; HANSEN, 2006; PIMENTA, 2011), sua influência no desempenho (KAHN; MENTZER, 1998; ELLINGER, 2000; HAUSMAN; MONTGOMERY; ROTH, 2002; O'LEARY-KELLY; FLORES, 2002; GIMENEZ; VENTURA, 2005) e os pontos de contato (ST. JOHN; RUE, 1991; LYNCH; WICKER, 2008; PAIVA, 2010; TURKULAINEN; KETOKIVI, 2012).

A integração interfuncional parte do princípio em que as funções trabalhando de forma isolada são incapazes de encontrar soluções satisfatórias para o negócio como um todo (KAHN; MENTZER, 1996). Para Mentzer, Stank e Esper (2008, p. 36), a integração interfuncional está compreendida no escopo da Gestão de Operações, definida como a “[...] aplicação de ferramentas analíticas e modelos para melhorar os processos de negócio que atravessam as fronteiras interfuncionais." Para estes autores, o foco da gestão de operações está também na melhoria da coordenação interfuncional dos pontos de contato existentes no negócio.

Ballou (2006, p. 42) define atividades de interface (ou pontos de contato) como "[...] aquelas que não se têm como administrar efetivamente em uma área funcional [...]", ou seja, requer para sua execução, a participação de mais de uma área ou função. A literatura de Gestão da Cadeia de Suprimentos e de Gestão de Operações conta com diversas contribuições para o estudo dos pontos de contato (SEZEN, 2005; JÜTTNER; CHRISTOPHER; BACKER, 2007; PIERCY, 2007; LYNCH; WHICKER, 2008). Porém, a maior parte desses estudos se limita a analisar o relacionamento entre pares de funções, ou díades. Neste trabalho, serão utilizadas as siglas: MKT para Marketing, LOG para Logística e PRO para Produção. Os Quadros 1, 2 e 3 sintetizam pontos de contato entre as díades Marketing-Produção (MKT-PROD), Marketing-Logística (MKT-LOG) e Logística-Produção (LOG-PROD) identificados na literatura.

Desde o artigo de Shapiro (1977), vários autores têm investigado a integração da díade MKT-PROD (WHYBARK, 1994; PARENTE, 1998; HAUSMAN; MONTGOMERY; ROTH, 2002; O'LEARY-KELLY; FLORES, 2002; PIERCY, 2007; SONG; SWINK, 2009; LYNCH; WHICKER, 2008). A literatura sugere que as interfaces entre as duas funções são frequentemente conflituosas (SHAPIRO, 1977), pois cada uma é orientada por diferentes objetivos. Swink e Song (2007) argumentam que, quando Marketing e Produção operam de forma alinhada, é possível 
reduzir o tempo para lançamento de novos produtos, aumentar a utilização dos ativos e, especialmente necessário, quando a empresa busca melhorar seu desempenho em múltiplos critérios competitivos ao mesmo tempo (PAIVA, 2010).

Considerando a díade MKT-LOG, destaca-se que Marketing é responsável por criar e gerenciar a demanda enquanto Logística se ocupa em satisfazer tal demanda (VAN HOEK; ELLINGER; JOHNSON, 2008; DAUGHERTY et al., 2009) por meio da disponibilização do produto, oferecendo um serviço confiável e eficiente para manter os preços em níveis competitivos (LAMBERT; COOPER; PAGH, 1998). Tanto Logística quanto Marketing são responsáveis por

Quadro 1. Pontos de contato da díade MKT-PROD e principais autores.

\begin{tabular}{|c|c|c|}
\hline Ponto de contato & Características & Principais autores \\
\hline Previsão de demanda & $\begin{array}{l}\text { Produção depende da previsão agregada para decidir em quanto } \\
\text { de capacidade será necessário investir e quais equipamentos } \\
\text { serão necessários. Alterações frequentes na demanda de curto } \\
\text { prazo (incluída a função Vendas) dificultam a programação da } \\
\text { produção; por outro lado, agilidade na resposta às necessidades } \\
\text { dos clientes (pronto atendimento) pode representar uma } \\
\text { vantagem competitiva. }\end{array}$ & $\begin{array}{l}\text { Shapiro (1977), St. John e } \\
\text { Rue (1991) Konijnendijk } \\
\text { (1994), Meijden, Nunen e } \\
\text { Ramondt (1994). }\end{array}$ \\
\hline Gestão de estoques & $\begin{array}{l}\text { Produção quer usar os estoques para manter os ciclos de } \\
\text { produção mais longos, suavizando assim a produção; já } \\
\text { Marketing quer usar os estoques de modo a garantir rápida } \\
\text { entrega para o cliente. }\end{array}$ & $\begin{array}{l}\text { Shapiro (1977), St. John e } \\
\text { Rue (1991). }\end{array}$ \\
\hline Qualidade & $\begin{array}{l}\text { Produção prioriza padrões de qualidade ou procedimentos } \\
\text { de monitoramento que não necessariamente medem os } \\
\text { verdadeiros parâmetros da qualidade do ponto de vista do } \\
\text { cliente; Marketing deseja adicionar diferenciais ao produto } \\
\text { que podem tornar os procedimentos de inspeção mais caros } \\
\text { e complexos. }\end{array}$ & $\begin{array}{l}\text { Shapiro (1977), St. John e } \\
\text { Rue (1991). }\end{array}$ \\
\hline $\begin{array}{c}\text { Gestão de SKU } \\
\text { (Stock Keeping Unit) }\end{array}$ & $\begin{array}{l}\text { Enquanto Marketing deseja uma linha de produtos ampla } \\
\text { para aumentar as vendas, fatias de mercado e a reputação da } \\
\text { empresa como fornecedora de uma linha completa, Produção } \\
\text { prefere manter uma linha de produtos mais restrita como } \\
\text { forma de manter baixos os custos de estoque, preparação de } \\
\text { máquina e para alteração da Produção. }\end{array}$ & $\begin{array}{l}\text { Shapiro (1977), St. John e } \\
\text { Rue (1991), Meijden, Nunen } \\
\text { e Ramondt (1994), Morgan, } \\
\text { Daniels e Kouvelis (2001), } \\
\text { Calantone, Dröge e Vickery } \\
\text { (2002). }\end{array}$ \\
\hline Controle de custos & $\begin{array}{l}\text { Quanto mais ampla for a linha de produtos, maiores tendem } \\
\text { a ser os custos de produção com ajustes de máquinas e } \\
\text { mudanças de linha. Quanto maiores os custos de produção, } \\
\text { menor flexibilidade na precificação Marketing terá. }\end{array}$ & $\begin{array}{l}\text { Shapiro (1977), St. John e } \\
\text { Rue (1991). }\end{array}$ \\
\hline $\begin{array}{l}\text { Desenvolvimento } \\
\text { de novos produtos/ } \\
\text { modificações em } \\
\text { produtos de linha }\end{array}$ & $\begin{array}{l}\text { Para a Produção, novos produtos podem necessitar novos } \\
\text { equipamentos e processos que tornam a operação produtiva } \\
\text { mais complexa. Em contrapartida, a disponibilização de novos } \\
\text { produtos no mercado pode representar uma possibilidade para } \\
\text { Marketing aumentar as vendas e a lucratividade. }\end{array}$ & $\begin{array}{l}\text { Shapiro (1977), St. John e } \\
\text { Rue (1991). }\end{array}$ \\
\hline Promoção & $\begin{array}{l}\text { Marketing sugere ações promocionais como forma de alavancar } \\
\text { as vendas; caso tais ações não sejam coordenadas com a } \\
\text { Produção, pode haver falta do produto promocional no mercado. } \\
\text { Além disso, a mobilização dos recursos produtivos para suprir } \\
\text { a demanda por produtos promocionais pode implicar na } \\
\text { impossibilidade de fabricar outros produtos de linha normal da } \\
\text { empresa, ocasionando ruptura no fornecimento destes. }\end{array}$ & $\begin{array}{l}\text { Shapiro (1977), Meijden, } \\
\text { Nunen e Ramondt (1994). }\end{array}$ \\
\hline Serviço ao cliente & $\begin{array}{l}\text { Marketing pode prometer entregar um pedido ao cliente } \\
\text { em um prazo sem consultar a capacidade da Produção em } \\
\text { cumprir com esse prazo. Para Produção, fornecer esse pedido } \\
\text { pode significar um aumento significativo nos custos, além } \\
\text { de prejudicar a programação da produção; para Marketing, } \\
\text { não cumprir com a promessa pode impactar negativamente } \\
\text { o relacionamento com o cliente, o que pode implicar em } \\
\text { redução das vendas a longo prazo. }\end{array}$ & $\begin{array}{l}\text { Shapiro (1977), Meijden, } \\
\text { Nunen e Ramondt (1994), } \\
\text { Greasley (2009). }\end{array}$ \\
\hline
\end{tabular}

Fonte: Elaborado pelos autores. 
Quadro 2. Pontos de Contato da díade MKT-LOG e principais autores.

\begin{tabular}{|c|c|c|}
\hline Pontos de Contato & Características & Principais autores \\
\hline Gestão de estoques & $\begin{array}{l}\text { Marketing prefere níveis de estoques mais elevados } \\
\text { de modo a atender prontamente a todos os pedidos; } \\
\text { Logística procura minimizar seus custos de } \\
\text { armazenagem por meio da redução de estoques. }\end{array}$ & $\begin{array}{l}\text { Voorhees et al. (1988), Lynch e } \\
\text { Whicker (2008). }\end{array}$ \\
\hline Gestão de SKU & $\begin{array}{l}\text { O número de itens no portfólio determina a quantidade } \\
\text { de SKU. Quanto maior o número de SKUs, maior } \\
\text { a probabilidade de o cliente ter suas necessidades } \\
\text { satisfeitas; em contrapartida, Logística enfrenta maior } \\
\text { dificuldade em manter níveis de estoque e taxas de } \\
\text { preenchimento do pedido adequadas. }\end{array}$ & $\begin{array}{l}\text { Rinehart, Cooper e Wagenheim } \\
\text { (1989). }\end{array}$ \\
\hline Processamento de pedidos & $\begin{array}{l}\text { O processamento de pedidos por meios eletrônicos } \\
\text { torna a Logística mais responsiva ao mercado, } \\
\text { melhorando também o serviço prestado ao cliente. A } \\
\text { visibilidade destes pedidos permite o atendimento/ } \\
\text { entrega de acordo com a necessidade do cliente. }\end{array}$ & $\begin{array}{l}\text { Rinehart, Cooper e Wagenheim } \\
\text { (1989). }\end{array}$ \\
\hline Embalagem & $\begin{array}{l}\text { Para chamar atenção do cliente, muitas vezes, } \\
\text { Marketing lança mão de embalagens com formas, } \\
\text { tamanhos e materiais diferenciados que, muitas } \\
\text { vezes, podem complicar a Logística na execução de } \\
\text { atividades como movimentação, seleção de modal e } \\
\text { aproveitamento do espaço (cubagem). }\end{array}$ & $\begin{array}{l}\text { Speh (1977), Lynagh e Poist } \\
\text { (1984), Voorhees et al. (1988), } \\
\text { Coyle, Bardi e Langley (2003), } \\
\text { Lynch e Whicker (2008). }\end{array}$ \\
\hline $\begin{array}{l}\text { Desenvolvimento de novos } \\
\text { produtos/modificações em } \\
\text { produtos de linha }\end{array}$ & $\begin{array}{l}\text { Logística deve estar atenta a todas as etapas } \\
\text { do processo de criação/alteração de produtos, } \\
\text { enxergando as possíveis consequências para sua } \\
\text { operação e comunicando para Marketing os possíveis } \\
\text { problemas técnicos ou práticos que venham a surgir. }\end{array}$ & Lynch e Whicker (2008). \\
\hline $\begin{array}{l}\text { Descontinuação de } \\
\text { produtos }\end{array}$ & $\begin{array}{l}\text { Marketing deve informar Logística com antecedência } \\
\text { em caso da descontinuidade de um determinado } \\
\text { produto de modo que Logística possa escoar esse } \\
\text { produto antes que este se torne obsoleto ou perca a } \\
\text { validade. }\end{array}$ & Lynch e Whicker (2008). \\
\hline $\begin{array}{c}\text { Armazenagem, picking e } \\
\text { distribuição }\end{array}$ & $\begin{array}{l}\text { Nem sempre há coordenação entre os pedidos a } \\
\text { serem entregues no dia e a disposição geográfica dos } \\
\text { clientes. Com melhor coordenação nesse aspecto, } \\
\text { a Logística pode otimizar seus custos de transporte } \\
\text { e melhorar seu nível de serviço, beneficiando } \\
\text { Marketing também. }\end{array}$ & $\begin{array}{l}\text { Rinehart, Cooper e Wagenheim } \\
\text { (1989), Lynch e Whicker } \\
(2008) .\end{array}$ \\
\hline Serviço ao cliente & $\begin{array}{l}\text { Logística e Marketing devem trabalhar em conjunto } \\
\text { de modo a definir os pacotes de serviços adequados } \\
\text { para cada perfil de cliente, oferecendo para cada } \\
\text { um apenas o conjunto de atributos que satisfará } \\
\text { suas necessidades em específico, para não saturar a } \\
\text { capacidade operacional. }\end{array}$ & $\begin{array}{l}\text { Voorhees et al. (1988), Lambert } \\
\text { e Cook (1990), Coyle, Bardi e } \\
\text { Langley (2003), Ballou (2006), } \\
\text { Lynch e Whicker (2008). }\end{array}$ \\
\hline Promoção & $\begin{array}{l}\text { Quando as promoções envolvem embalagens } \\
\text { promocionais especiais, Logística e Marketing } \\
\text { encontram problemas com o timing da ação } \\
\text { promocional. Isso acontece porque a indústria sabe } \\
\text { quando o produto saiu da fábrica, mas não sabe } \\
\text { exatamente quando este foi disposto na prateleira do } \\
\text { varejista. }\end{array}$ & $\begin{array}{l}\text { Rinehart, Cooper e Wagenheim } \\
\text { (1989), Ellinger (2000), Coyle, } \\
\text { Bardi e Langley (2003). }\end{array}$ \\
\hline Precificação & $\begin{array}{l}\text { Descontos servem para influenciar o tamanho do } \\
\text { pedido do cliente. Espera-se que quanto maior o } \\
\text { desconto, maior será o tamanho do pedido médio; } \\
\text { porém, uma estrutura de descontos mal projetada } \\
\text { pode levar a pedidos Premium antieconômicos, } \\
\text { considerando restrições de consolidação de carga. }\end{array}$ & $\begin{array}{l}\text { Rinehart, Cooper e Wagenheim } \\
\text { (1989), Coyle, Bardi e Langley } \\
\text { (2003), Ballou (2006), Lynch e } \\
\text { Whicker (2008). }\end{array}$ \\
\hline
\end{tabular}

Fonte: Elaborado pelos autores. 
Quadro 3. Pontos de contato da díade LOG-PROD e principais autores.

\begin{tabular}{|c|c|c|}
\hline Pontos de Contato & Características & Principais autores \\
\hline Gestão de estoque & $\begin{array}{l}\text { Produção busca economias de escala com longos ciclos de } \\
\text { produção; tal opção pode implicar elevação do nível de estoque } \\
\text { de determinados produtos, aumentando assim os custos } \\
\text { logísticos. }\end{array}$ & $\begin{array}{l}\text { Bowersox e Closs (2001), } \\
\text { Coyle, Bardi e Langley } \\
(2003) \text {. }\end{array}$ \\
\hline Lead time & $\begin{array}{l}\text { Produção tem interesse em reduzir o lead time com o intuito } \\
\text { de oferecer respostas mais rápidas ao mercado; entretanto, } \\
\text { muitas vezes, os tempos de espera dos caminhões para o } \\
\text { descarregamento dos produtos no cliente não é levado em conta } \\
\text { no planejamento feito pela Produção. }\end{array}$ & $\begin{array}{l}\text { Jin, Luo e Eksioglu } \\
\text { (2008), Kuhlang, Edtmayr } \\
\text { e Sihn (2011). }\end{array}$ \\
\hline $\begin{array}{l}\text { Previsão da } \\
\text { demanda }\end{array}$ & $\begin{array}{l}\text { Com o intuito de reduzir custos e evitar situações de pressa, } \\
\text { Produção procura antecipar ao máximo a produção sazonal. } \\
\text { Tal antecipação pode ser inviabilizada devido à elevação dos } \\
\text { custos de armazenagem. Produção e Logística devem planejar } \\
\text { conjuntamente uma produção sazonal economicamente viável. }\end{array}$ & $\begin{array}{l}\text { Coyle, Bardi e Langley } \\
(2003) \text {. }\end{array}$ \\
\hline Suprimentos & $\begin{array}{l}\text { É preciso garantir que os itens serão pedidos, transportados } \\
\text { e recebidos de acordo com os prazos e níveis de qualidade } \\
\text { estabelecidos. }\end{array}$ & $\begin{array}{l}\text { Bowersox e Closs (2001), } \\
\text { Coyle, Bardi e Langley } \\
\text { (2003), Christopher (2005). }\end{array}$ \\
\hline $\begin{array}{l}\text { Armazenagem, } \\
\text { picking e } \\
\text { distribuição }\end{array}$ & $\begin{array}{l}\text { Estocagem e despacho requerem ação conjunta. Para a Produção, } \\
\text { a embalagem de proteção contribui para conservar os atributos } \\
\text { da qualidade do produto; para Logística, contribui na unitização } \\
\text { da carga e cubagem; Logística pode facilitar a entrada da } \\
\text { matéria-prima na linha de produção com abastecimento eficiente } \\
\text { e Produção pode facilitar a retirada do produto final da linha } \\
\text { para que Logística possa armazenar ou despachar. Normalmente, } \\
\text { a Produção executa sua programação sem considerar possíveis } \\
\text { restrições de roteirização da frota da Logística. }\end{array}$ & $\begin{array}{l}\text { Bowersox e Closs (2001), } \\
\text { Coyle, Bardi e Langley } \\
\text { (2003), Christopher (2005), } \\
\text { Scholz-Reiter, Frazzon e } \\
\text { Makuschewitz (2010). }\end{array}$ \\
\hline
\end{tabular}

Fonte: Elaborado pelos autores.

disponibilizar o produto no tempo e nas quantidades corretas e a colaboração entre eles é extremamente importante em um momento no qual a diferenciação cada vez mais se dá em função do nível de serviço oferecido. O Quadro 1 sintetiza os principais pontos de contato entre MKT-PROD levantados.

O pessoal de Logística está entre os poucos que não fazem parte nem de Marketing nem de Vendas/Comercial que "tocam" o cliente e, em geral, representam o último ponto de contato do cliente com a organização (ELLINGER; ELLINGER; KELLER, 2002). Este último "toque" implica oportunidades de captar mais informações a respeito do que o cliente valoriza em termos dos produtos e serviços prestados e os desafios envolvidos para a coordenação da cadeia (EMERSON; GRIMM, 1996; ELLINGER, 2000). Contribui também para Marketing e para empresa como um todo, na medida em que estas ações colaboram para a construção da imagem da marca (HILLETOFTH; ERICSSON; CHRISTOPHER, 2009). O Quadro 2 sintetiza os principais pontos de contato desta díade.

Considerando a díade LOG-PROD, observa-se que tanto Logística quanto Produção se preocupam com o impacto que suas decisões têm sobre o custo, sobre o lead time e sobre o abastecimento eficiente de matéria-prima (SEZEN, 2005; GIMENEZ, 2006). O alinhamento entre Logística e Produção traz vantagens para atividades de Compras, produção just in time, redução de custos e aumento na velocidade de entrega (SEZEN, 2005). O Quadro 3 mostra os pontos de contato identificados na díade LOG-PROD.

A identificação dos pontos de contato nas díades apresentada até aqui contribui para aprofundar o conhecimento sobre os principais pontos de contato entre Marketing, Logística e Produção já identificados na literatura. É possível notar que alguns deles se repetem em mais de uma díade, sugerindo que algumas dessas atividades demandam esforços das três funções concomitantemente. As sobreposições são identificadas quando o mesmo ponto de contato é citado em mais de uma díade, como se pode observar no Quadro 4.

A princípio pode parecer que a revisão da literatura sobre díades não sugere que as funções de Marketing, Logística e Produção desenvolvam atividades conjuntamente. Entretanto, nota-se que alguns pontos de contato podem ser entendidos como subitens de pontos de contato mais abrangentes, por exemplo, o ponto de contato relacionado ao lead time pode ser visto como um dos componentes do ponto de contato nível de serviço (CHRISTOPHER, 2005). Optou-se 
por não fazer tal consideração devido ao fato de muitos pontos de contato listados no Quadro 4 não terem os papéis das funções descritos de maneira clara na literatura. Além disso, as nomenclaturas utilizadas são distintas apesar de diversos pontos sugerirem certa proximidade, por exemplo, seleção do canal de distribuição e localização do canal.

Diferentes funções podem estar envolvidas com o processo de oferecer melhor nível de serviço ao cliente. Entretanto, Marketing, Logística e Produção são as mais diretamente envolvidas, pois o mercado tem demandado cada vez mais que as organizações construam diferenciais (RINEHART; COOPER; WAGENHEIM, 1989; CHRISTOPHER, 2005). Neste sentido, alcançar o "pedido perfeito" ou "vender certo e não mais", como argumentado por Mollenkopf, Frankel e Russo (2011), pode ser a base para a criação de um padrão de serviço.

\section{Metodologia}

Este trabalho consiste em uma pesquisa qualitativa exploratória, na qual, em uma primeira etapa, uma revisão da literatura existente sobre os temas relacionados foi realizada. Na segunda etapa, foi conduzido um estudo de caso, procurando fazer uma articulação com a literatura revisada.

A revisão de literatura foi conduzida na base de dados EBSCOhost e Google Scholar, utilizando palavras-chave e operadores booleanos do tipo "E" e "OU". A pesquisa foi classificada quanto à relevância em relação às palavras-chave e os cem primeiros artigos tiveram seus resumos lidos. Como critério de seleção, os artigos que não identificavam a caracterização de pontos de contato foram descartados.
Os artigos selecionados foram lidos na íntegra e classificados em pastas virtuais de acordo com os principais temas abordados no texto. Além disso, ao longo da leitura dos artigos selecionados, outras referências citadas nos artigos buscados e que se adequavam ao critério de seleção foram adicionados. Ao final, foram selecionadas 20 referências, que estão citadas nos Quadros 1, 2 e 3 da revisão de literatura. Nas bases buscadas, priorizaram-se artigos publicados em periódicos que tivessem revisão por pares. Bancos de teses e congressos nacionais também foram buscados em uma fase inicial do trabalho, mas os poucos trabalhos surgiram e não foram utilizados neste artigo por não estarem diretamente ligados à temática.

A estratégia de pesquisa utilizada foi o estudo de caso, que é capaz de prover uma caracterização empírica de um fenômeno e mostra-se adequado para captá-los de forma completa e profunda em ambientes dinâmicos, como os encontrados na pesquisa em Gestão de Operações (MEREDITH, 1998; YIN, 2001; BOYER; SWINK, 2008; MIGUEL, 2010). A exemplo de estudos de casos em temáticas relacionadas, publicados na última década como Pagell (2004), Oliva e Watson (2011) e Mollenkopf, Frankel e Russo (2011), buscou-se analisar um caso, realizando entrevistas em profundidade com colaboradores das três áreas funcionais, bem como de outras áreas consideradas de apoio, que também vivenciam a integração interfuncional e compartilham seus resultados. Optou-se pela realização de um estudo de caso em uma empresa do setor de bebidas, denominada aqui Empresa A. O Quadro 5 mostra os critérios de seleção do caso.

Quadro 4. Síntese dos pontos de contato entre MKT, LOG e PROD.

\begin{tabular}{|c|c|c|c|}
\hline Pontos de Contato & MKT-PROD & MKT-LOG & LOG-PROD \\
\hline Gestão de SKU & $X$ & $\mathrm{X}$ & \\
\hline Promoção & $\mathrm{X}$ & $\mathrm{X}$ & \\
\hline Descontinuação de produtos & & $\mathrm{X}$ & \\
\hline $\begin{array}{l}\text { Desenvolvimento de novos produtos/ modificações em produtos } \\
\text { de linha }\end{array}$ & $\mathrm{X}$ & $\mathrm{X}$ & \\
\hline Lead Time & & & $\mathrm{X}$ \\
\hline Precificação & & $X$ & \\
\hline Previsão de demanda & $\mathrm{X}$ & & $\mathrm{X}$ \\
\hline Planejamento e controle da produção e transporte & & & $\mathrm{X}$ \\
\hline Armazenagem, picking e distribuição & & $\mathrm{X}$ & $\mathrm{X}$ \\
\hline Controle de Custos & $\mathrm{X}$ & & \\
\hline Embalagem & & $\mathrm{X}$ & $\mathrm{X}$ \\
\hline Gestão de Estoques & $\mathrm{X}$ & $\mathrm{X}$ & \\
\hline Qualidade & $\mathrm{X}$ & & \\
\hline Processamento de pedido & & $\mathrm{X}$ & \\
\hline Serviços ao cliente & $\mathrm{X}$ & $\mathrm{X}$ & \\
\hline
\end{tabular}


Quadro 5. Critérios para seleção da organização participante.

\begin{tabular}{|c|l|}
\hline Critério & \multicolumn{1}{c|}{ Definição } \\
\hline $\begin{array}{c}\text { Ser uma empresa de porte } \\
\text { médio ou grande }\end{array}$ & $\begin{array}{l}\text { Quanto maior a organização, mais complexas são as ações de integração } \\
\text { interfuncional demandadas, envolvendo maior volume de recursos gastos com o } \\
\text { processo, variados níveis de descentralização de decisões e dispersão física das } \\
\text { atividades (MASSEY; DAWES, 2001; PAIVA, 2010). }\end{array}$ \\
\hline $\begin{array}{c}\text { Possuir departamentos } \\
\text { distintos de Marketing, } \\
\text { Logística e Produção }\end{array}$ & $\begin{array}{l}\text { Este critério reflete a necessidade de coletar informações por meio de diferentes } \\
\text { agentes, buscando uma opinião cruzada entre eles, no intuito de obter confiabilidade } \\
\text { das informações. }\end{array}$ \\
\hline $\begin{array}{c}\text { Possuir pontos de contato } \\
\text { entre as funções de } \\
\text { Marketing, Logística e } \\
\text { Produção }\end{array}$ & $\begin{array}{l}\text { Esse critério foi previamente identificado por meio de entrevistas exploratórias } \\
\text { com pessoas da alta administração, ou com pessoas capazes de indicar potenciais } \\
\text { entrevistados e autorizar a realização da pesquisa. }\end{array}$ \\
\hline $\begin{array}{c}\text { Estar inserida em um } \\
\text { ambiente mercadológico } \\
\text { turbulento }\end{array}$ & $\begin{array}{l}\text { Mercados extremamente competitivos demandam que as organizações desenhem } \\
\text { soluções diferenciadas de cadeia de suprimentos ao invés de um único padrão para todos } \\
\text { os seus clientes. As empresas devem combinar diversas estratégias de suprimentos, } \\
\text { produção e distribuição a fim de atender às condições específicas de seus produtos e } \\
\text { mercados atendidos (HILLETOFTH; ERICSSON; CHRISTOPHER, 2009). }\end{array}$ \\
\hline $\begin{array}{c}\text { Estar localizada até no } \\
\text { máximo 500 km da sede da } \\
\text { pesquisa }\end{array}$ & $\begin{array}{l}\text { Por questões de limite de tempo e de orçamento. Dessa forma, tornou-se viável } \\
\text { a realização de múltiplas visitas, dentro de um período de tempo limitado } \\
\text { (PAGELL, 2004). }\end{array}$ \\
\hline
\end{tabular}

Além de atender aos critérios listados no Quadro 5, o caso selecionado compreende uma organização que vem nos últimos dez anos investindo na melhoria do alinhamento interfuncional. $\mathrm{O}$ caso permitiu caracterizar os pontos de contato e identificar como estes contribuem para a melhoria do desempenho do negócio como um todo. A Empresa A está inserida em um mercado bastante dinâmico e competitivo (bebidas), que demanda elevada sincronia entre atividades relacionadas a Marketing, Logística e Produção. Além disso, a visão da alta administração a respeito da importância da integração demandasuprimento, o amplo acesso a entrevistas pessoais, a permissão para participação na reunião de um grupo interfuncional dedicado ao alinhamento interfuncional (Planejamento Integrado ou PI) e o acesso a documentos secundários fazem dela um caso de destaque em relação a outros oriundos do projeto de pesquisa mais amplo do qual este trabalho faz parte.

A empresa A é franqueada de uma grande companhia de bebidas, fabricando e distribuindo bebidas carbonatadas e não carbonatadas como: refrigerante, cerveja, água mineral, suco, chá, energético, hidrotônico e isotônico. Sediada no Estado de São Paulo, atende a aproximadamente 25 mil clientes distribuídos em 136 municípios localizados em parte dos estados de Minas Gerais e São Paulo. Com faturamento acima de $\mathrm{R} \$ 500$ milhões por ano e 2.500 funcionários, é considerada uma empresa de grande porte para o setor em que atua.

As entrevistas duraram entre 30-100 minutos e foram conduzidas individualmente com o auxílio de um questionário semiestruturado que contemplava assuntos de interesse retirados da revisão de literatura sobre os pontos de contato entre Marketing, Logística e Produção (CARTER; ELLRAM, 1998; ROGERS et al., 2002). A adoção deste tipo de instrumento permitiu entender mais a fundo os pressupostos que governam as interações entre os gerentes de Marketing, Logística e Produção (McCRACKEN, 1988), ao passo que estimulava os entrevistados a darem respostas mais francas e detalhadas (ELLINGER; KELLER; HANSEN, 2006). O Apêndice 1 sintetiza os principais pontos abordados no questionário.

O foco das entrevistas foi a apreensão das percepções individuais dos diretores, gerentes e coordenadores de diferentes áreas funcionais foco da pesquisa (Marketing, Logística e Produção), e por diretores, gerentes e coordenadores de funções consideradas apoio a elas, como Comercial, Recursos Humanos, Financeiro. Optou-se por entrevistar, no mínimo, 2 indivíduos de cada área foco. Para a escolha dos entrevistados das áreas de apoio, considerou-se a indicação do executivo, que deu abertura ao estudo de caso, incluindo pessoas da área comercial (pela possível interface com Marketing) e de funções que estivessem envolvidas em comitês interfuncionais já existentes. Como na empresa A obteve-se grande abertura para coleta de informação e alguns entrevistados sugeriam colegas que eram importantes no fenômeno pesquisado, finalizou-se o estudo de caso com 7 entrevistados de Marketing, 5 de Produção e 2 de Logística, sendo que a diretora de operações responde ao mesmo tempo por ambas as áreas (Logística e Produção). Quanto às funções consideradas apoio, contabilizaram-se 5 entrevistados. Dessa forma, foram entrevistadas pessoas das funções principais a respeito do fenômeno estudado e também 
pessoas de funções que mantinham contato com as funções de Marketing, Logística e Produção, denominadas, nessa pesquisa, como funções de apoio. As funções de apoio que participaram das entrevistas foram identificadas ao início de cada estudo de caso. Pessoas nessas funções de apoio foram questionadas sobre sua 'visão externa' da integração entre Marketing, Logística e Produção. A intenção desta estratégia foi obter uma visão multidimensional da percepção da integração entre estas duas funções, em detrimento da possível limitação gerada por percepções parciais das funções em foco.

Foram selecionados indivíduos de diferentes níveis hierárquicos para evitar percepções tendenciosas acerca dos pontos de contato. Phillips (1981) ressalta a importância das percepções dos gerentes no processo de pesquisa porque eles estão mais envolvidos com as atividades gerenciais funcionais e interfuncionais e, por esses motivos, podem contribuir com comentários válidos sobre o problema em estudo. Além disso, o superintendente e o gerente de planejamento estratégico também foram entrevistados. Ao todo, realizaram-se 19 entrevistas entre abril e outubro de 2011.

No Quadro 6, pode-se observar quem foram os entrevistados, bem como suas respectivas áreas. Destaca-se que cada cargo recebeu códigos que serão usados na apresentação e discussão dos dados.

Além das entrevistas, outras fontes de evidências foram utilizadas para análise, incluindo visitas à planta, participação de pesquisadores na reunião de Planejamento Integrado e uso de materiais impressos fornecidos pela empresa ou obtidos de fontes secundárias. A codificação e a análise primária dos dados foram realizadas por dois dos autores e depois combinadas a fim de garantir a robustez sugerida por Butterfield et al. (2005). Como sugerido por Mollenkopf, Frankel e Russo (2011), múltiplas fontes de evidência provenientes de observação, transcrição das entrevistas e relatos da reunião de Planejamento Integrado foram utilizados para enriquecer a análise. Os dados obtidos nas entrevistas foram gravados, transcritos e submetidos à técnica de análise de conteúdo. Segundo Bauer e Gaskell (2002), a análise de conteúdo consiste no estudo de transcrições textuais de dados, visando comparar, observar diferenças e categorizar fatores presentes no texto por meio do processamento da informação. Tal processamento proporciona a identificação objetiva e sistemática de características específicas. Com base nas recomendações de Lindgreen (2001), Bauer e Gaskell (2002) e Bardin (2008), os passos utilizados para a realização da análise de conteúdo nesta pesquisa estão descritos a seguir.

Transcrição das entrevistas em profundidade gravadas em áudio: as entrevistas foram transcritas de modo a facilitar a análise textual e aproveitar trechos essenciais do discurso na escrita da análise. Em seguida, realizou-se uma pré-análise das transcrições: leitura rápida, identificação prévia de possíveis categorias, com base na teoria observada no referencial. No passo seguinte, foi executada

Quadro 6. Perfil dos entrevistados.

\begin{tabular}{|c|c|c|c|}
\hline \multicolumn{2}{|r|}{ Cargo } & Unidade de Análise & Código \\
\hline 1 & Diretor Superintendente & Marketing & DS \\
\hline 2 & Gerente de Marketing & Marketing & GM \\
\hline 3 & Coordenador de Trade Marketing & Marketing & CTM \\
\hline 4 & Diretor Comercial & Marketing & $\mathrm{DC}$ \\
\hline 5 & Gerente Comercial & Marketing & GC \\
\hline 6 & Coordenador Comercial & Marketing & $\mathrm{CC}$ \\
\hline 7 & Encarregada do Planejamento Comercial & Marketing & $\mathrm{EC}$ \\
\hline 8 & Diretora de Operações & Logística/Produção & DO \\
\hline 9 & Gerente de Logística & Logística & GL \\
\hline 10 & Coordenador de Logística & Logística & $\mathrm{CL}$ \\
\hline 11 & Gerente Industrial & Produção & GI \\
\hline 12 & Gerente da Qualidade & Produção & GQ \\
\hline 13 & Gerente de Equipamentos & Produção & GE \\
\hline 14 & Coordenador de Suprimentos & Produção & $\mathrm{CS}$ \\
\hline 15 & Coordenadora de Controladoria & Apoio & CCONT \\
\hline 16 & Gerente de Controladoria & Apoio & GCONT \\
\hline 17 & Gerente de Planejamento Estratégico & Apoio & GPE \\
\hline 18 & Gerente de RH & Apoio & GRH \\
\hline 19 & Gerente do Call Center & Apoio & GCC \\
\hline
\end{tabular}


uma análise aprofundada: leitura sistemática das transcrições orientada pela separação de frases no texto e relacionamento destas orações com unidades de registro, definidos pela sua representação semântica. Além da análise do texto escrito, foi analisado o áudio de todas as entrevistas, para obter segurança na identificação de expressões audíveis, que viessem a alterar o contexto ou sentido semântico da frase. Depois de localizar as unidades de registro (o que foi realizado pelo primeiro e segundo autor em conjunto), o significado particular de cada em destes elementos foi disposto em quadros, considerando as respostas de cada entrevistado e, em seguida, caracterizado em profundidade. A categorização seguiu o padrão da revisão de literatura, agrupando as unidades de registros em díades e a partir delas, tentando obter a tríade.

Destaca-se que, para a última etapa que compreendeu análise da categorização feita, o protocolo utilizado permitiu que os entrevistados refletissem sobre variadas situações que exigiam alinhamento entre as três funções. No que se refere à validação teórica, esse protocolo de coleta de dados foi elaborado com base em conceitos preexistentes na literatura. $\mathrm{Na}$ análise, foi realizada uma articulação entre os resultados de campo e os trabalhos mencionados no referencial teórico.

\section{Apresentação e discussão do estudo de caso}

\subsection{Caracterização da Empresa A e dos entrevistados}

Diversas são as características presentes na indústria de bebidas que a torna interessante para o estudo da integração interfuncional. A primeira é a dificuldade em garantir a disponibilidade de toda a linha de produtos em diversos canais de distribuição, os quais variam desde grandes redes varejistas até pequenos bares e padarias. Isso exige uma grande sincronia entre Marketing/Comercial, Logística e Produção. Outros fatores que exigem esforços de integração são: perecibilidade de seus produtos finais, alto volume de produção, picos de sazonalidade e ações promocionais de nível nacional veiculadas pela companhia franqueadora.

Para lidar com essa complexidade, foi criado há dez anos na Empresa A um grupo interfuncional composto por representantes de diversas funções, inclusive de Marketing, Logística e Produção. O Planejamento Integrado (PI), como é conhecido, se reúne semanalmente com o intuito de discutir soluções para as principais questões operacionais, mercadológicas e administrativas encontradas no dia a dia da empresa. De modo a estimular os colaboradores, a alta administração da Empresa A evita participar das reuniões do grupo, conferindo autonomia para decisões operacionais e interferindo somente em casos especiais. A responsabilidade e autonomia concedidas aos integrantes do PI lhes confere o status de "agentes de processos" (GPE), ou seja, elas são responsáveis por tornar o planejamento integrado o fórum referência para questões de integração interfuncional na Empresa A.

\subsection{Pontos de contato observados nas Díades}

A partir das entrevistas realizadas, percebeu-se a existência de quatro pontos de contato entre MKT-PROD. O objetivo comum que rege a interface entre as funções é a disponibilidade do produto, uma diretriz definida pelo planejamento estratégico da empresa (DS). Produção deve cumprir com as campanhas e prazos sinalizados por Marketing e informar a função Suprimentos nos casos em que haverá cortes na produção para que sejam adquiridos produtos de outra franquia.

Se não entregar, o consumidor será influenciado pela mídia, que vai criar o desejo de consumo e ele não vai ter o produto para consumir. Vai gerar frustração no consumidor (CTM).

Todos os pontos de contato entre MKT-PROD estão descritos no Quadro 7, assim como alguns exemplos citados nas entrevistas.

No Quadro 7, aparece a função Comercial como presente na díade MKT-PROD, nos pontos de contato: promoções/embalagens, gestão de SKU e previsão de demanda. Apesar de não ser foco inicial deste estudo, a atividade realizada pelo Comercial nas organizações está de modo geral alocada a uma área separada de Marketing. Percebe-se então nestas atividades, não uma díade, mas uma tríade formada por MKT-PROD e Comercial.

No Quadro 8, que considera a díade MKT-LOG, novamente a função Comercial aparece nos pontos de contato nível de serviço e visibilidade/comunicação com o ponto de venda. A necessidade de integração entre MKT, Comercial e LOG advém basicamente da disponibilização do produto no ponto de venda cujos impactos relacionam-se com as atividades de lançamento de produtos, nível de serviço, degustações, gestão de estoques, entrega, campanhas promocionais entre outras. No Quadro 8, são descritos os principais pontos de contato dessa díade.

A integração entre Logística e Produção é alta, pois as funções estão em contato diariamente retirando produto da linha e reabastecendo-a com vasilhames retornáveis o que acaba gerando diversas sinergias entre as funções. Entretanto, alguns conflitos operacionais como parada de linha por problemas logísticos com 
Quadro 7. Pontos de Contato entre MKT e PROD na empresa analisada.

\begin{tabular}{|c|c|c|}
\hline Ponto de Contato & Descrição & Exemplo citado \\
\hline $\begin{array}{l}\text { Lançamento de } \\
\text { Produtos }\end{array}$ & $\begin{array}{l}\text { Marketing recebe } \\
\text { cronograma da } \\
\text { franqueadora e discute } \\
\text { com Produção. Em caso } \\
\text { de impossibilidade de } \\
\text { cumpri-lo, Marketing } \\
\text { renegocia com } \\
\text { Franqueadora. }\end{array}$ & $\begin{array}{l}\text { "[...] vamos dizer assim, a principal informação que eu preciso do } \\
\text { marketing é a respeito de lançamentos de produtos e ações que vão } \\
\text { ser feitos no mercado. Então, uma vez que marketing tem lá o seu } \\
\text { cronograma de embalagens, de lançamentos, porque, às vezes, pode } \\
\text { não ser um lançamento, mas é uma modificação em uma embalagem, } \\
\text { por exemplo, para alguma promoção específica [...]" (GI). }\end{array}$ \\
\hline $\begin{array}{l}\text { Promoções/ } \\
\text { Embalagens }\end{array}$ & $\begin{array}{l}\text { Marketing e Comercial } \\
\text { acompanham e repassam } \\
\text { previsão de demanda } \\
\text { buscando ajuste com } \\
\text { Produção. }\end{array}$ & $\begin{array}{l}\text { "Algumas promoções são comunicadas na embalagem, então, } \\
\text { Produção tem que se preparar para produzir os produtos contendo } \\
\text { essas embalagens promocionais na data programada. Se Produção } \\
\text { atrasar a produção, quando a campanha promocional for encerrada } \\
\text { ainda haverá produtos em estoque [...] quanto antes o Marketing } \\
\text { avisar sobre qualquer mudança de campanha, mudança de } \\
\text { rótulo, isto vai ajudá-los muito (funcionários da Produção) a se } \\
\text { programar." (CTM). }\end{array}$ \\
\hline Gestão de SKU & $\begin{array}{l}\text { Dinamismo exige } \\
\text { acompanhamento } \\
\text { constante da díade } \\
\text { (ou tríade, no caso de } \\
\text { envolver o Comercial } \\
\text { também) para retirar do } \\
\text { portfólio produtos de } \\
\text { baixo giro. }\end{array}$ & $\begin{array}{l}\text { "Em alguns momentos a área Comercial, a área de Marketing, em } \\
\text { conjunto, elas necessitam de algumas ações específicas de mercado } \\
\text { que são, vamos dizer assim, embalagens diferenciadas, ou produtos } \\
\text { diferenciados, que podem causar algum tipo de transtorno... onde e } \\
\text { os lotes são muito pequenos." (GI). }\end{array}$ \\
\hline $\begin{array}{l}\text { Previsão de } \\
\text { demanda }\end{array}$ & $\begin{array}{l}\text { Responsabilidade do } \\
\text { Comercial e precisa ser } \\
\text { aprovada pela Produção. } \\
\text { Marketing também está } \\
\text { envolvido por trazer } \\
\text { informação do mercado. }\end{array}$ & $\begin{array}{l}\text { "Então, ou seja, eu sei o que eu tenho que produzir toda semana, } \\
\text { pela previsão de vendas que vem lá da área comercial, que vem lá } \\
\text { do planejamento de vendas... o marketing, aí, na verdade, ele tem } \\
\text { que estar muito alinhado com a área comercial, no caso, porque } \\
\text { normalmente o principal...vamos dizer assim, a principal informação } \\
\text { que eu preciso do marketing é a respeito de lançamentos de produtos } \\
\text { e ações que vão ser feitos no mercado.” (GI). }\end{array}$ \\
\hline
\end{tabular}

armazenagem ainda ocorrem. O PI tem um papel importante na integração dessas duas áreas, pois, nessas reuniões, são discutidas questões de lotes, momento de produção, chegada de matéria-prima na área de suprimentos, tudo levando em consideração a área de armazenagem. No Quadro 9, os pontos de contato entre Logística e Produção são descritos e exemplificados com falas dos entrevistados.

\subsection{A tríade Marketing-Logística-Produção}

Considerando as díades observadas no estudo de caso é possível repetir a mesma lógica utilizada no Quadro 4 para predizer um possível comportamento da tríade com base nas principais sobreposições encontradas. O Quadro 10, a seguir, apresenta tais sobreposições. Destaca-se que aqui se considera apenas uma inferência a respeito do que foi mencionado sobre as díades e do que foi dito a respeito da tríade especificamente.

Nas respostas diretas dos entrevistados, o "lançamento de produtos" foi o único ponto de contato citado entre a tríade MKT-LOG-PROD. Entretanto, outros comentários ao longo das transcrições descreviam a necessidade de alinhamento entre as três funções em diferentes atividades. Na Empresa A, é fundamental que MKT disponibilize o cronograma de lançamentos de produtos juntamente com a previsão de demanda para que a PROD e LOG possam programar suas capacidades de modo a atender às quantidades definidas, dentro dos prazos pré-estabelecidos. A imprevisibilidade da demanda representa um grande complicador para as funções se planejarem, no caso de novos produtos. Diferente do que foi observado no caso, na literatura, este ponto de contato demandava alinhamento entre as díades MKT-PROD e MKT-LOG (SHAPIRO, 1977; ST. JOHN; RUE, 1991; LYNCH; WHICKER, 2008).

Outros pontos foram sugeridos como demandantes de alinhamento em díades: previsão da demanda; promoção; transporte (entrega); nível de serviço; planejamento e sequenciamento da produção; planejamento da capacidade logística; e embalagens.

A previsão da demanda compreende duas etapas na Empresa A. Na primeira, o Comercial tem uma equipe dedicada que utiliza modelos históricos em 
Quadro 8. Pontos de Contato MKT e LOG na empresa analisada.

\begin{tabular}{|c|c|c|}
\hline Ponto de Contato & Descrição & Exemplo citado \\
\hline $\begin{array}{l}\text { Lançamento de } \\
\text { produto }\end{array}$ & $\begin{array}{l}\text { Logística busca entender } \\
\text { como novos produtos } \\
\text { impactarão a movimentação } \\
\text { de materiais, armazenamento, } \\
\text { unitização e gestão de } \\
\text { estoques; já Marketing } \\
\text { garante que a comunicação } \\
\text { com o cliente seja mais } \\
\text { eficaz. }\end{array}$ & $\begin{array}{l}\text { "Marketing organiza treinamentos com o pessoal da Logística } \\
\text { para degustação e informação sobre novos produtos, na } \\
\text { intenção de aprimorar a comunicação com os compradores, } \\
\text { nos pontos de entrega, estimulando vendas futuras [...] É } \\
\text { um trabalho de lançamento, então a gente senta, vê... É } \\
\text { tudo formalizado, né. A partir do momento que você faz a } \\
\text { campanha, já planeja esse treinamento." (GM). }\end{array}$ \\
\hline Gestão de SKU & $\begin{array}{l}\text { Marketing incentiva o } \\
\text { desenvolvimento de diversos } \\
\text { produtos que aumentam o } \\
\text { número de SKUs a ser gerido } \\
\text { pela Logística. }\end{array}$ & $\begin{array}{l}\text { "Marketing quer ter todos os tamanhos, todos os sabores, todos } \\
\text { os... as cores, todas as garrafas diferenciadas, tudo o que você } \\
\text { puder dar pra Marketing ainda é pouco." (GL). "Na realidade } \\
\text { Marketing gosta de complicar. Marketing está sempre trazendo } \\
\text { inovações, embalagens novas, lançamentos. E sempre que } \\
\text { uma nova embalagem, por exemplo, é desenvolvida então a } \\
\text { atividade de armazenamento é complicada." (CTM). }\end{array}$ \\
\hline $\begin{array}{l}\text { Previsão de } \\
\text { demanda }\end{array}$ & $\begin{array}{l}\text { Logística se planeja } \\
\text { para atender à demanda, } \\
\text { Marketing define prioridades } \\
\text { de atendimento a clientes. }\end{array}$ & $\begin{array}{l}\text { "O melhor dos mundos seria planejar adequadamente, diminuir } \\
\text { a produção, vender muito bem e não ter contingências a ser } \\
\text { feitas." (GM). }\end{array}$ \\
\hline Entrega eficiente & $\begin{array}{l}\text { Treinamento do pessoal de } \\
\text { transporte que é chave para } \\
\text { garantir nível de serviço ao } \\
\text { cliente e trazer informações } \\
\text { do mercado para Marketing. }\end{array}$ & $\begin{array}{l}\text { "[...] (uma entrega ineficiente) vai gerar um impacto negativo } \\
\text { no nível de serviço que nós entregamos ao cliente. Um } \\
\text { exemplo é no momento do aumento de preço. Nós avisamos } \\
\text { o cliente para que ele se abasteça porque na próxima semana } \\
\text { o preço irá aumentar. Se Logística não entregar na data, o } \\
\text { cliente fez o pedido com o preço antigo, mas pagará o preço } \\
\text { reajustado.” (CC). }\end{array}$ \\
\hline $\begin{array}{l}\text { Gestão de } \\
\text { Estoques }\end{array}$ & $\begin{array}{l}\text { Entregador retira os produtos } \\
\text { danificados enquanto realiza } \\
\text { a gestão de estoques do } \\
\text { cliente (FEFO). }\end{array}$ & $\begin{array}{l}\text { "Quando ele entrega, ele tem contato com produtos com } \\
\text { avarias, com uma série de coisas... tanto na área de fundo, } \\
\text { estoque, quanto também nas prateleiras [...] auxiliando nesta } \\
\text { comunicação."(GM). }\end{array}$ \\
\hline Promoção & $\begin{array}{l}\text { Marketing e Logística } \\
\text { trabalham disponibilidade } \\
\text { e publicidade, assim como } \\
\text { eventos. }\end{array}$ & $\begin{array}{l}\text { "Então, o caminhão para numa avenida de uma cidade de } 60 \\
\text { mil habitantes, por exemplo, fica 10, 15, } 20 \text { minutos fazendo } \\
\text { um trabalho de descarregamento, entrega... Naquele momento } \\
\text { que ele parou, ele é um outdoor."(GM). }\end{array}$ \\
\hline Embalagens & $\begin{array}{l}\text { Decisões relacionadas } \\
\text { a mudanças ou ações } \\
\text { promocionais são decididas } \\
\text { em conjunto, pois impactam } \\
\text { custo de transporte. }\end{array}$ & $\begin{array}{l}\text { “Às vezes, por conta de } 1 \mathrm{~cm} \text { e, às vezes, por conta de } \\
\text { meio milímetro na embalagem, o pallet no final poderia } \\
\text { ser melhor... o volume dele poderia ser melhor, poderia ser } \\
\text { melhor composto. Então isso ajuda no ganho de viagens, com } \\
\text { carretas.... imagina que cada pallet, você tem lá.... uma perda } \\
\text { de } 10 \mathrm{~cm} \text { na composição das camadas, que você tenha uma } \\
\text { perda de } 10 \text { cm quadrado por camada... isso no final do ano, } \\
\text { daria quantas caixas?" (GL). }\end{array}$ \\
\hline Nível de serviço & $\begin{array}{l}\text { Marketing, Comercial e } \\
\text { Logística procuram não } \\
\text { causar nenhum tipo de } \\
\text { frustração no cliente. }\end{array}$ & $\begin{array}{l}\text { “[...] a gente sai na rua, pra explicar, para mostrar o conceito } \\
\text { deste produto, desta promoção para eles conhecerem um } \\
\text { momento antes, porque fica no mínimo desagradável um cara } \\
\text { tá entregando uma caixa de um produto que ele nem sabe o que } \\
\text { é aquilo lá, ele pega na nota e fala o que é que é isso?” (GM). }\end{array}$ \\
\hline $\begin{array}{l}\text { Visibilidade/ } \\
\text { Comunicação } \\
\text { com o ponto de } \\
\text { venda }\end{array}$ & $\begin{array}{l}\text { O entregador (Logística) } \\
\text { reforça as ações de Marketing } \\
\text { e do Comercial. }\end{array}$ & $\begin{array}{l}\text { "O entregador tem muito contato com o ponto de venda, o } \\
\text { consumidor que pergunta, aborda, porque ele chega geralmente } \\
\text { num horário comercial e as pessoas estão... sei lá, num bar, } \\
\text { por exemplo, bebendo alguma coisa, um refrigerante ou } \\
\text { uma cerveja, e eles costumam interferir, querendo saber de } \\
\text { alguma coisa... e este cara treinado pode ajudar na questão de } \\
\text { visibilidade do produto, de falar bem desta marca." (GM). }\end{array}$ \\
\hline
\end{tabular}


Quadro 9. Pontos de Contato entre LOG e PRO na empresa analisada.

\begin{tabular}{|c|c|c|}
\hline Ponto de Contato & Descrição & Exemplo citado \\
\hline $\begin{array}{l}\text { Lançamento de } \\
\text { produto }\end{array}$ & $\begin{array}{l}\text { Exige coordenação para que } \\
\text { o produto seja lançado no } \\
\text { prazo e evitar a ruptura dos } \\
\text { outros produtos. }\end{array}$ & $\begin{array}{l}\text { "[...] quando a gente vai lançar um produto, eles (Logística) } \\
\text { têm movimentação... então é uma questão de matéria-prima, } \\
\text { de produto que está saindo de linha e entrando uma outra... } \\
\text { então, o PI principalmente tem representantes da Produção } \\
\text { que estão sabendo, junto com a gente, muito antes das coisas } \\
\text { acontecerem... } 6 \text { meses antes.” (GM). }\end{array}$ \\
\hline Nível de serviço & $\begin{array}{l}\text { Ambas desenvolvem } \\
\text { flexibilidade para demandas } \\
\text { diferenciadas. }\end{array}$ & $\begin{array}{l}\text { "Por que que eu preciso vender uma caixa de refrigerante com } \\
24 \text { latas? Então a gente consegue fazer, por exemplo, pacotes } \\
\text { com tamanhos menores para clientes menores." (GL). }\end{array}$ \\
\hline Movimentação & $\begin{array}{l}\text { Logística cuida das } \\
\text { embalagens retornáveis e } \\
\text { conservação do palete trazido } \\
\text { do cliente também da retirada } \\
\text { do produto acabado da linha } \\
\text { para estoque de produto } \\
\text { acabado e distribuição. }\end{array}$ & $\begin{array}{l}\text { "Então se eu trouxer mais ordenado possível, menos bagunçado } \\
\text { entra na linha. Se eu trouxer, é... eu tenho uma área de } \\
\text { classificação de vasilhames, quanto melhor eu fizer isso, menos } \\
\text { eu tenho problema na linha. A condição de palete, a condição } \\
\text { de paletização, como esse produto está entrando na linha [...] } \\
\text { esse tempo entre abastecimento de linha e retirada de produto } \\
\text { pra ir pro estoque, a logística tem que fazer um belo trabalho de } \\
\text { revisão de layout e tempos e movimentos porque pode acontecer } \\
\text { gargalo. Aí no final do dia, você vai agrupando, } 5 \text { min aqui, } 10 \\
\text { ali, } 20 \text { lá, quando você vê... a indústria parou a linha uma hora e } \\
\text { meia que seja só por problemas logísticos." (GL). }\end{array}$ \\
\hline $\begin{array}{l}\text { Programação } \\
\text { da produção/ } \\
\text { transferência }\end{array}$ & $\begin{array}{l}\text { Troca de informação } \\
\text { sobre programação de } \\
\text { produção e entrega, evitando } \\
\text { desabastecimento. }\end{array}$ & $\begin{array}{l}\text { "Então se eu consigo entender com a Logística, a forma com } \\
\text { que vai ser entregue, ou quando é que ele vai emitir a nota } \\
\text { ou até mesmo a transferência para os depósitos... né, para os } \\
\text { centros de distribuição, eu consigo otimizar também o meu } \\
\text { processo de produção." (GI). }\end{array}$ \\
\hline $\begin{array}{l}\text { Revisão do } \\
\text { planejamento da } \\
\text { produção }\end{array}$ & $\begin{array}{l}\text { Semanalmente planejamento } \\
\text { de produção revisa a oferta/ } \\
\text { demanda e avalia como } \\
\text { isso vai influenciar o } \\
\text { planejamento da logística. }\end{array}$ & $\begin{array}{l}\text { “[...] em períodos onde a demanda é muito alta e nossa } \\
\text { capacidade de produção não é suficiente para atender à } \\
\text { demanda, ou seja, (eu devo) ou estocar previamente ou } \\
\text { adquirir produtos de fora. A logística, na verdade, me ajuda } \\
\text { nesse momento, a tomar melhor a decisão em termos de } \\
\text { programação da produção. Porque eu tenho linhas de produção } \\
\text { aqui, dependendo do tipo de embalagem, né... as linhas são } \\
\text { basicamente dedicadas.” (GI). }\end{array}$ \\
\hline $\begin{array}{l}\text { Programaçãoda } \\
\text { produção/ } \\
\text { estoque }\end{array}$ & $\begin{array}{l}\text { Decisões em termos de } \\
\text { lotes a serem produzidos e } \\
\text { armazenados são tomadas por } \\
\text { Logística e Produção. }\end{array}$ & $\begin{array}{l}\text { "Então o produto Y, cada vez que eu faço ele eu produzo.... } 20 \\
\text { mil caixas, que é um batch (lote) mínimo de produção. Só que } \\
\text { a minha demanda é de mil caixas por dia, por exemplo. Então } \\
\text { esse é um produto que a hora que eu colocar ele no estoque vai } \\
\text { me levar o nível do estoque dele pra } 20 \text { dias mais ou menos. } \\
\text { Mas eu não tenho uma outra alternativa, porque eu não consigo } \\
\text { fazer lotes menores." (CL). }\end{array}$ \\
\hline Manutenção & $\begin{array}{l}\text { Antecipando paradas } \\
\text { programadas de linha, } \\
\text { ambas se preparam para } \\
\text { produzir e armazenar } \\
\text { volumes de modo a evitar } \\
\text { que haja desabastecimento do } \\
\text { mercado. }\end{array}$ & $\begin{array}{l}\text { "Ele tem que enxergar que ele vai ter uma semana sem } \\
\text { produção, ele tem que puxar o estoque... ele vai aumentar } \\
\text { os dias de estoque, aumentando os dias de estoque ele corre } \\
\text { dois riscos: 1) na Logística, que eu posso não ter lugar pra } \\
\text { armazenar. Aí eu tenho que de repente contratar um armazém } \\
\text { ou um macrogalpão pra isso; ou 2) eu posso também correr o } \\
\text { risco de produtos daquela linha que tá parada, eu posso correr } \\
\text { o risco desse produto ficar muito velho no meu estoque, por } \\
\text { conta do shelf-life." (CL). }\end{array}$ \\
\hline $\begin{array}{l}\text { Aumento da } \\
\text { capacidade }\end{array}$ & $\begin{array}{l}\text { Ambas olham para questões } \\
\text { de layout tendo em mente as } \\
\text { áreas para movimentação de } \\
\text { materiais e armazenagem. }\end{array}$ & $\begin{array}{l}\text { "Um dos ganhos que nós tivemos foi em toda a nossa logística } \\
\text { de armazenagem ser através do WMS... que possibilita a área } \\
\text { de armazenagem enxergar através das ordens de produção, o } \\
\text { que vai ser enviado pro estoque e diante dessa informação, a } \\
\text { pessoa que tá gerenciando o estoque ela já consegue visualizar } \\
\text { se ela vai ter espaço pra armazenar, se ela não vai ter espaço, } \\
\text { se ela vai ter que fazer alguma movimentação adicional no } \\
\text { salão pra poder tá é... acondicionando esses produtos, então ela } \\
\text { consegue se antecipar." (CL). }\end{array}$ \\
\hline
\end{tabular}


Quadro 9. Continuação...

\begin{tabular}{|c|c|c|}
\hline Ponto de Contato & Descrição & Exemplo citado \\
\hline $\begin{array}{l}\text { Garantia da } \\
\text { qualidade }\end{array}$ & $\begin{array}{l}\text { Produção deve garantir } \\
\text { que todos os produtos } \\
\text { fabricados sairão da linha } \\
\text { seguindo todos os padrões } \\
\text { pré-estabelecidos pela } \\
\text { franqueadora e Logística } \\
\text { deve garantir que nenhuma } \\
\text { de suas atividades prejudicará } \\
\text { o padrão de qualidade do } \\
\text { produto. }\end{array}$ & $\begin{array}{l}\text { "Por exemplo, o produto não pode ficar armazenado no sol. O } \\
\text { produto não pode ficar armazenado próximo a vasilhames, a } \\
\text { parte retornável, porque existe a contaminação cruzada como } \\
\text { a gente chama [...]. No picking, na área de picking eu tenho } \\
\text { que ter recursos pra que a movimentação não danifique o } \\
\text { produto [...] por exemplo, eu tenho um suco, né, que é aquela } \\
\text { embalagem, ele é uma caixinha desse tamanhozinho assim, } \\
\text { com } 12 \text { unidades supersensível, uma embalagem cartonada. Eu } \\
\text { não posso colocar ele embaixo e colocar uma caixa de cerveja } \\
\text { em cima, certo?" (CL). }\end{array}$ \\
\hline
\end{tabular}

Quadro 10. Sobreposições das díades observadas no estudo de caso.

\begin{tabular}{|l|c|c|c|c|}
\hline \multicolumn{1}{|c|}{ Pontos de Contato } & MKT-PROD & MKT-LOG & LOG-PROD & TRÍADE \\
\hline Lançamento de produtos & $\mathrm{X}$ & $\mathrm{X}$ & $\mathrm{X}$ & $\mathrm{X}$ \\
\hline Promoção/Embalagem & $\mathrm{X}$ & $\mathrm{X}$ & & \\
\hline Amplitude e profundidade da linha & $\mathrm{X}$ & $\mathrm{X}$ & & \\
\hline Previsão de demanda/vendas & $\mathrm{X}$ & $\mathrm{X}$ & & \\
\hline Entrega eficiente & & $\mathrm{X}$ & & \\
\hline Campanhas promocionais & & $\mathrm{X}$ & & \\
\hline Nível de serviço & & $\mathrm{X}$ & $\mathrm{X}$ & \\
\hline Visibilidade/Comunicação com o ponto de venda & & $\mathrm{X}$ & & \\
\hline Movimentação de materiais & & & $\mathrm{X}$ & \\
\hline Programação da produção & & & $\mathrm{X}$ & \\
\hline Programação de produção/ Nível de Estoque & & & $\mathrm{X}$ & \\
\hline Manutenção & & & $\mathrm{X}$ & \\
\hline Aumento da Capacidade & & & $\mathrm{X}$ & \\
\hline Garantia da Qualidade & & & $\mathrm{X}$ & \\
\hline
\end{tabular}

conjunto com as percepções dos consultores de vendas para a definição da previsão de demanda irrestrita (sem considerar capacidades operacionais). Na segunda etapa, esses números são compartilhados com PROD e LOG (usualmente na reunião do PI) para que cada área exponha sua perspectiva sobre as capacidades operacionais de modo a traduzir a previsão de demanda em previsão de vendas. Ou seja, procura-se um consenso entre as três funções para que o Comercial venda apenas o que PROD e LOG se comprometem a produzir e entregar, respectivamente. $\mathrm{Na}$ literatura, este ponto era definido apenas para a díade MKT-PROD (SHAPIRO, 1977; ST. JOHN; RUE, 1991; KONIJNENDIJK, 1994; MEIJDEN; NUNEN; RAMONDT, 1994) e LOG-PROD (COYLE; BARDI; LANGLEY, 2003). Observa-se que, nesse contexto, a integração não deve se limitar a tríade MKT-LOG-PROD, mas também incluir o Comercial e Suprimentos.

Atividades de promoção também foram apontadas como relevantes. Alguns entrevistados citaram a questão da confiabilidade da previsão de demanda dado o comportamento incerto do consumidor perante a ação promocional. Tal incerteza dificulta o planejamento das capacidades produtivas e logísticas da Empresa A. O MKT realiza também o endomarketing, difundindo os novos produtos e informações sobre eles principalmente para o pessoal de LOG (que faz a ponte com cliente). Na teoria, também apenas as díades MKT-PROD (SHAPIRO, 1977; MEIJDEN; NUNEN; RAMONDT, 1994) e MKT-LOG (RINEHART; COOPER; WAGENHEIM, 1989; ELLINGER, 2000; COYLE; BARDI; LANGLEY, 2003) eram mencionadas para esta atividade.

A partir dos pontos de contato Lançamento de Produto, Previsão da demanda e Promoção, deriva-se outro ponto de contato: o planejamento/ sequenciamento da produção e planejamento da capacidade logística. Na Empresa A, os planejamentos operacionais são definidos semanalmente na reunião do PI após a avaliação dos calendários de lançamentos de produtos, de promoções e do planejamento de demanda. A atividade de entrega/transporte é outro ponto de contato entre a tríade, pois a responsabilidade em transportar o produto é da LOG; no entanto, se MKT e Comercial não disponibilizarem seus cronogramas de lançamentos de produtos e de promoção, a Produção não terá tempo suficiente para 
planejar sua capacidade e acionar os fornecedores para cumprir com os pedidos. Consequentemente, LOG terá dificuldades em disponibilizar o produto seguindo os prazos acordados com os clientes.

A atividade nível de serviço requer integração nas díades MKT-LOG e LOG-PROD. Para a definição e operacionalização do nível de serviço ao cliente, a Logística deve se adequar a padrões de atendimentos registrados no CRM, que é administrado por Marketing, e dessa forma, atender a diferentes níveis de exigência de clientes. Além disso, o planejamento do nível de serviço feito em conjunto pode gerar entregas eficientes ao cliente. Para o CL, é importante que MKT defina as características dos diferentes grupos de clientes e discuta com LOG soluções adequadas ao atendimento. Esse ponto de contato requer atividades integradas entre as três funções como: definir quais clientes e em quais situações a entrega pode ser feita depois de 24 horas, definir quais clientes devem ter prioridade e, em caso de grandes pedidos, deve haver planejamento conjunto com cronogramas de entrega definidos em conjunto com LOG e PROD (adequar estoques, capacidade das duas áreas para que não seja preciso contratar transporte de terceiros, onerando os custos finais aos clientes).

A gestão de estoques é outra atividade que, apesar de na teoria só ter sido apontada como atividade de interface da díade MKT-LOG (VOORHEES et al., 1988; LYNCH; WHICKER, 2008) e MKT-PROD (SHAPIRO, 1977; ST. JOHN; RUE, 1991), também foi identificada como pertencente à tríade. De acordo com os entrevistados, a demanda varia muito ao longo do ano e, muitas vezes, tal variação é imprevisível (por exemplo, mudança climática), o que naturalmente complica o planejamento de LOG e PROD. Em momentos de demanda mais baixa, PROD não pode deixar de produzir; isso porque, caso aconteça um pequeno incremento na demanda, o mercado pode ficar desabastecido; também deve considerar que trabalhar com elevado nível de capacidade ociosa é pouco adequado. LOG por sua vez tem maior flexibilidade em aumentar sua capacidade de entrega (com contratação de freteiros), porém a capacidade de armazenamento é limitada. Sendo assim, é comum haver uma negociação com MKT para que, em situações de baixa demanda, seja incentivado o consumo de um determinado produto com o intuito de baixar os níveis de estoque. Em complemento, em situações de consumo mais aquecido, as três funções podem decidir por reduzir as vendas de determinado produto para que o mercado não sofra com desabastecimento, ou por negociar esse volume extra com outras franquias (opção mais frequente na Empresa A).

O ponto de contato embalagens, que, na teoria, só havia sido apontado como interface entre MKT-LOG (SPEH, 1977; LYNAGH; POIST,
1984; VOORHEES et al., 1988; COYLE; BARDI; LANGLEY, 2003; LYNCH; WHICKER, 2008), também parece necessitar do envolvimento de PROD na tomada de decisão. É muito comum haver revisões nos grafismos, formatos e materiais que compõem as embalagens, acompanhadas de ações publicitárias que requerem uma grande sincronia das diferentes ações das três funções. Outros pontos de contato, que incluíam outras áreas que não eram objeto da pesquisa, foram mencionados, entretanto optou-se por não discuti-los aqui por falta de espaço.

\section{Conclusão e implicações gerenciais}

A integração interfuncional entre MKT, LOG e PROD é um fenômeno complexo e, a partir do caso estudado, percebeu-se que, mesmo buscando explorar a tríade, várias interfaces com outras áreas funcionais despontaram como Comercial (Vendas) e Suprimentos, dentre outras. Neste artigo, o objetivo foi identificar os principais pontos de contato entre Marketing, Logística e Produção, de modo a aprofundar a compreensão sobre o alinhamento interfuncional entre as três funções e sua contribuição para o alcance dos objetivos organizacionais. $\mathrm{O}$ caso revelou que parece ser consenso a ideia de que a ruptura do produto no ponto de venda é ruim para os resultados da empresa como um todo e não apenas para as métricas de uma área. $\mathrm{O}$ único ponto de contato da tríade MKT-LOG-PROD, identificado no caso diretamente, foi o lançamento de produtos. Observando a literatura, este ponto era indicado como demandante de contato apenas entre as díades MKT-PROD e MKT-LOG (SHAPIRO, 1977; ST. JOHN; RUE, 1991; LYNCH; WHICKER, 2008).

Considerando a díade MKT e PROD, contrastando pontos de contato observados nos casos e na literatura, apontam-se atividades de lançamento de produtos (SHAPIRO, 1977; ST. JOHN; RUE, 1991); promoção (SHAPIRO, 1977; MEIJDEN; NUNEN; RAMONDT, 1994); amplitude e profundidade da linha (SHAPIRO, 1977; ST. JOHN; RUE, 1991; MEIJDEN; NUNEN; RAMONDT, 1994; MORGAN; DANIELS; KOUVELIS, 2001; CALANTONE; DRÖGE; VICKERY, 2002); previsão da demanda (SHAPIRO, 1977; ST. JOHN; RUE, 1991; KONIJNENDIJK, 1994; MEIJDEN; NUNEN; RAMONDT, 1994). O ponto de contato embalagem foi citado no estudo de caso, mas não havia surgido na literatura. Não foram verificados, como apontado pela literatura, os pontos: gestão de estoques (SHAPIRO, 1977; ST. JOHN; RUE, 1991); qualidade (SHAPIRO, 1977; ST. JOHN; RUE, 1991); controle de custos (SHAPIRO, 1977; ST. JOHN; RUE, 1991); serviço ao cliente (SHAPIRO, 1977; MEIJDEN; NUNEN; RAMONDT, 1994; GREASLEY, 2009).

Na díade MKT e LOG, o caso confirma os pontos levantados pela literatura como: lançamento de produto (LYNCH; WHICKER, 2008); gestão de SKU 
(RINEHART; COOPER; WAGENHEIM, 1989); previsão de demanda, entrega eficiente (RINEHART; COOPER; WAGENHEIM, 1989; LYNCH; WHICKER, 2008); gestão de estoques (VOORHEES et al., 1988; LYNCH; WHICKER, 2008); promoção (RINEHART; COOPER; WAGENHEIM, 1989; ELLINGER, 2000; COYLE; BARDI; LANGLEY, 2003); embalagens (SPEH, 1977; LYNAGH; POIST, 1984; VOORHEES et al., 1988; COYLE; BARDI; LANGLEY, 2003; LYNCH; WHICKER, 2008); nível de serviço (VOORHEES et al., 1988; LAMBERT; COOK, 1990; COYLE; BARDI; LANGLEY, 2003; BALLOU, 2006; LYNCH; WHICKER, 2008). Nesta díade, foi identificada a construção de visibilidade/ comunicação com o ponto de venda como um ponto de contato, ainda não vislumbrado pela literatura. Não foram verificados, conforme apontado pela literatura, o processamento de pedidos (RINEHART; COOPER; WAGENHEIM, 1989), precificação (RINEHART; COOPER; WAGENHEIM, 1989; COYLE; BARDI; LANGLEY, 2003; BALLOU, 2006; LYNCH; WHICKER, 2008).

Na díade LOG-PROD, o caso confirmou apenas dois pontos de contato citados na literatura: movimentação (BOWERSOX; CLOSS, 2001; COYLE; BARDI; LANGLEY, 2003; CHRISTOPHER, 2005; SCHOLZREITER; FRAZZON; MAKUSCHEWITZ, 2010), programação de produção/estoque (BOWERSOX; CLOSS, 2001; COYLE; BARDI; LANGLEY, 2003). Como pontos de contato não revelados na literatura anterior para esta díade, encontraram-se neste caso: lançamento de produto; nível de serviço; programação da produção/transferência; replanejamento da produção; manutenção; aumento da capacidade; e garantia da qualidade. A literatura ainda apontava os pontos de contato: lead time (JIN; LUO; EKSIOGLU, 2008; KUHLANG; EDTMAYR; SIHN, 2011); previsão da demanda (COYLE; BARDI; LANGLEY, 2003); suprimentos (BOWERSOX; CLOSS, 2001; COYLE; BARDI; LANGLEY, 2003; CHRISTOPHER, 2005); e armazenagem, picking e distribuição (BOWERSOX; CLOSS, 2001; COYLE; BARDI; LANGLEY, 2003; CHRISTOPHER, 2005; SCHOLZ-REITER; FRAZZON; MAKUSCHEWITZ, 2010).

Alguns aspectos distintivos na problemática de integração interfuncional foram levantados no caso da empresa A e talvez expliquem, em parte, alguns dos pontos encontrados. O primeiro deles é o fato de a indústria de bebidas ter seu negócio fundamentado em grandes ações de Marketing, realizadas principalmente pelas grandes corporações internacionais, obriga que as funções internas da organização se mobilizem para cumprir com as diretrizes repassadas. Um segundo aspecto é o apoio da alta administração da Empresa A para questões interfuncionais, cumprindo esta um papel relevante em estimular uma visão mais sistêmica em detrimento da visão estritamente funcional, como recomendado na literatura sobre o tema (MURPHY; POIST, 1996; RHO; HAHM; YU, 1994; MOLLENKOPF; GIBSON; OZANNE, 2000; PAGELL, 2004). A estruturação do comitê de PI foi uma iniciativa da alta administração e hoje é considerado pelos entrevistados como a maior referência na resolução de problemas interfuncionais.

Outro ponto apreendido da análise é o papel fundamental que as funções de MKT, LOG E PROD desempenham na dicotomia demanda/oferta, já mencionados por Mollenkopf, Frankel e Russo (2011, p. 401) sobre a preocupação em vender certo e não necessariamente aumentar continuamente os volumes sem a respectiva retaguarda interna.

Vender melhor não é só empurrar o produto para o mercado, mas... fazer com que o consumidor perceba a diferença de ter um produto nosso no mercado. (GC).

Além disso, observa-se que a integração entre as três funções é mais clara nos níveis mais altos da organização, tendendo a reduzir de intensidade conforme se aproxima dos níveis mais operacionais. Pela percepção dos entrevistados, a integração em nível operacional é dificultada pelo menor grau de interação (KAHN; MENTZER, 1996) que o exigido em outras funções na rotina desses funcionários, fruto da sua especialização em determinadas atividades (LAWRENCE; LORSCH, 1967).

Este artigo oferece duas contribuições. A primeira delas é explorar de forma aprofundada os pontos de contato entre Marketing, Logística e Produção, considerando a visão de díades e tríade. Seguindo este foco e considerando apenas um estudo de caso, percebeu-se a participação de outras funções que também devem ser incluídas quando se pretende estudar de forma mais ampla a gestão interfuncional. A segunda e talvez mais importante refere-se ao fato de que se observou, em vários pontos de contato entre MKT-PROD (promoções/embalagens, gestão de SKU e previsão de demanda), a necessidade de integração interfuncional com a função Comercial. Também na díade MKT-LOG, a função Comercial desponta nos pontos de contato do nível de serviço e visibilidade/comunicação com o ponto de venda. Isso mostra a importância de se acrescentar a função Comercial às díades. Springinklee e Wallenburg (2012), em um estudo recente sobre a integração Logística-Produção para a melhoria do desempenho do serviço de distribuição, sugerem que pesquisas futuras devem expandir a visão para a tríade incluindo Marketing e Comercial. Seguindo esta sugestão, podem ser pesquisados em maior detalhe e comparados os interrelacionamentos entre Produção, Logística, Marketing e Vendas. 
Um ponto a ser destacado ainda é a revisão de literatura ter sugerido que os pontos de contato encontrados possuem diversas nomenclaturas e, muitas vezes, não são descritos de maneira detalhada, o que dificulta o entendimento sobre o papel de cada função para um determinado ponto de contato. Ressalta-se que uma limitação do presente estudo foi a adoção de um estudo de caso único que, apesar de ter se mostrado relevante para o estudo, não permite contrapontos com outros casos dos resultados encontrados. Dessa forma, pesquisas qualitativas futuras podem ser realizadas em outros setores da economia, de modo a complementar o arcabouço conceitual sobre os pontos de contato entre essas três funções, escasso em investigações de natureza qualitativa.

\section{Agradecimentos}

Os autores agradecem à FAPESP os auxílios concedidos ao longo desta pesquisa: com bolsas (processos $n^{\circ}$ 2009/05160-0 e 2011/01657-8) e auxílio pesquisa (processo no 2011//06008-8).

\section{Referências}

BALLOU, R. H. Gerenciamento da cadeia de suprimentos/logística empresarial. 5. ed. Porto Alegre: Bookman, 2006.

BARRATT, M. Understanding the meaning of collaboration in the supply chain. Supply Chain Management: An International Journal, v. 9, n. 1, p. 30-42, 2004. http:// dx.doi.org/10.1108/13598540410517566

BARDIN, L. Análise de conteúdo. Lisboa: Edições 70, 2008.

BAUER, M. W.; GASKELL, G. Pesquisa qualitativa com texto, imagem e som. Manual prático. Petrópolis: Vozes, 2002.

BOWERSOX, D.; CLOSS, D. Logística Empresarial: O Processo de Integração da Cadeia de Suprimento. Atlas: São Paulo, 2001.

BOYER, K.; SWINK, M. Empirical Elephants-Why multiple methods are essential to quality research in operations and supply chain management. Journal of Operations Management, v. 26, n. 1, p. 337-348, 2008. http://dx.doi.org/10.1016/j.jom.2008.03.001

BUTTERFIELD, L. D. et al. Fifty years of the critical incident technique: 1954-2004 and beyond. Qualitative Research, v. 5, n. 4, p. 475-497, 2005. http://dx.doi. org/10.1177/1468794105056924

CALANTONE, R.; DRÖGE, C.; VICKERY, S. Investigating the manufacturing-marketing interface in new product development: does context affect the strength of relationships? Journal of Operations Management, v. 20, n. 1, p. 273-287, 2002. http://dx.doi.org/10.1016/ S0272-6963(02)00009-8

CARTER, C.; ELLRAM, L. Reverse Logistics: A review of titerlture and framework for future investigation. Journal Of Business Logistics, v. 19, n. 1, p. 85-102, 1998.

CHRISTOPHER, M. Logistics and supply chain management: Creating value-adding networks. 3rd ed. London: Prentice Hall, 2005.
COYLE, J. J.; BARDI, E. J.; LANGLEY, C. J. The Management Of Business Logistics: A Supply Chain Perspective. 7 ed. Thomson Learning, 2003.

DAUGHERTY, P. J. et al. Marketing/logistics relationships: influence on capabilities and performance. Journal of Business Logistics, v. 30, n. 1, p. 1-18, 2009. http:// dx.doi.org/10.1002/j.2158-1592.2009.tb00096.x

ELLINGER, A. E. Improving Marketing/Logistics crossfunctional collaboration in the supply chain. Industrial Marketing Management, v. 29, n. 1, p. 85-96, 2000. http://dx.doi.org/10.1016/S0019-8501(99)00114-5

ELLINGER, A. E.; ELLINGER, A. D.; KELLER, S. B. Logistics managers learning environments and firm performance. Journal of Business Logistics, v. 23, n. 1, p. 19-38, 2002. http://dx.doi. org/10.1002/j.2158-1592.2002.tb00014.x

ELLINGER, A. E.; KELLER, S. B.; HANSEN J.D. Bridging the divide between logistics and Marketing: facilitating collaborative behavior. Journal of Business Logistic, v. 27, n. 2, p. 1-28, 2006. http://dx.doi. org/10.1002/j.2158-1592.2006.tb00215.x

EMERSON, C. J.; GRIMM, C. M. Logistics and Marketing components of customer service: an empirical test of the Mentzer, Gomes and Krapfel model. International Journal of Physical Distribution \& Logistics Management, v. 26, n. 8, p. 29-42, 1996. http://dx.doi. org/10.1108/09600039610128258

FAWCETT, S. E.; MAGNAN, G. M.; McCARTER, M. W. Benefits, barriers, and bridges to effective supply chain management. Supply Chain Management: An International Journal, v. 13, n. 1, p. 35-48, 2008. http:// dx.doi.org/10.1108/13598540810850300

GIMENEZ, C. Logistics integration processes in the food industry. International Journal of Physical Distribution \& Logistics Management, v. 36, n. 3, p. 231-249, 2006. http://dx.doi.org/10.1108/09600030610661813

GIMENEZ, C.; VENTURA, E. Logistics-production, logistics-marketing and external integration: their impact on performance. International Journal of Operations \& Production Management, v. 25, n. 1, p. 20-38, 2005. http://dx.doi.org/10.1108/01443570510572222

GREASLEY, A. Operations Management. 2nd ed. Hoboken: John Wiley \& Sons, 2009.

HAUSMAN, W. H.; MONTGOMERY, D. B.; ROTH, A. V. Why should Marketing And Manufacturing work together? Some exploratory empirical results. Journal of Operations Management, v. 20, n. 1, p. 241-257, 2002. http://dx.doi.org/10.1016/S0272-6963(02)00010-4

HILLETOFTH, P.; ERICSSON, D.; CHRISTOPHER, M. Demand chain management: a Swedish industrial case study. Industrial Management \& Data System, v. 109, n. 9, p. 1179-1196, 2009.

JIN, M.; LUO, Y.; EKSIOGLU, S. D. Integration of production sequencing and outbound logistics in the automotive industry. International Journal of Production Economics, v. 113, n. 1, p. 766-774, 2008. http://dx.doi.org/10.1016/j.ijpe.2007.11.003

JÜTTNER, U.; CHRISTOPHER, M.; BACKER, S. Demand chain management-integrating marketing and supply chain management. Industrial Marketing Management, 
v. 36, n. 3, p. 377-392, 2007. http://dx.doi.org/10.1016/j. indmarman.2005.10.003

JÜTTNER, U.; CHRISTOPHER, M.; GODSELL, J. A strategic framework for integrating marketing and supply chain strategies. International Journal of Logistics Management, v. 21, n. 1, p. 104-126, 2010. http:// dx.doi.org/10.1108/09574091011042205

KAHN, K. B. Interdepartmental Integration: A definition with implications for product Development Performance. Journal of Production and Innovation Management, v. 13, n. 1, p. 137-151, 1996. http:// dx.doi.org/10.1016/0737-6782(95)00110-7

KAHN, K. B.; MENTZER, J. T. Logistics and interdepartmental integration. International Journal of Physical Distribution \& Logistics, v. 26, n. 8 , p. 6-14, 1996. http://dx.doi. org/10.1108/09600039610182753

KAHN, K. B.; MENTZER, J. T. Marketing's integration with other departments. Journal of Business Research, v. 42, n. 1, p. 53-62, 1998. http://dx.doi.org/10.1016/ S0148-2963(97)00068-4

KONIJNENDIJK, P. A. Coordinating marketing and manufacturing in ETO companies. International Journal of Production Economics, v. 37, n. 1, p. 19-26, 1994. http://dx.doi.org/10.1016/0925-5273(94)90004-3

KUHLANG, P.; EDTMAYR, T.; SIHN, W. Methodical approach to increase productivity and reduce lead time in assembly and production-logistic processes. Journal of Manufacturing Science and Technology, v. 4, n. 1, p. 24-32, 2011. http://dx.doi.org/10.1016/j. cirpj.2011.02.001

LAMBERT, D.; COOK, R. Integrating Marketing and Logistics for increased profit. Business, v. 40, n. 3, p. 22-29, 1990.

LAMBERT, D. M.; COOPER, M. C.; PAGH, J. D. Supply chain management: implementation issues and research opportunities. International Journal of Logistics Management, v. 9, n. 2, p. 1-19, 1998. http://dx.doi. org/10.1108/09574099810805807

LAWRENCE, P.; LORSCH, J. Organization and Environment: Managing Differentiation and Integration. Boston: Harvard University, 1967.

LINDGREEN, A. A framework for studying relationship Marketing dyads. Qualitative Market Research, v. 4, n. 2, p. 75-87, 2001. http://dx.doi. org/10.1108/13522750110388572

LYNAGH, P.; POIST, R. Assigning organizational responsibility for interface activities: an analysis of PD and marketing manager preferences. International Journal of Physical Distribution and Materials Management, v. 16, n. 6, p. 34-46, 1984. http://dx.doi. org/10.1108/eb014595

LYNCH, J.; WHICKER, L. Do logistics and marketing understand each other? An empirical investigation of the interface activities between logistics and marketing. International Journal of Logistics: Research and Applications, v. 11, n. 3, p. 167-178, 2008. http://dx.doi. org/10.1080/13675560701602708

MASSEY, G.; DAWES, P. Integrating Marketing and Sales: The frequency and effectiveness of methods used in Australia and the United Kingdom. In: ANZMAC 2001
CONFERENCE, 2001, Auckland. Proceedings... Massey University, 2001. $10 \mathrm{p}$.

McCRACKEN, G. The long interview. California: Sage Publications, 1988.

MEIJDEN, L. H.; NUNEN, A. E. E.; RAMONDT, A. Forecasting - bridging the gap between Sales and Manufacturing. International Journal of Production Economic, v. 37, n. 1, p. 101-114, 1994. http://dx.doi. org/10.1016/0925-5273(94)90011-6

MENTZER, J. T.; STANK, T.; ESPER, T. L. Defining SCM and its relationship to Logistics, Marketing, Manufacturing and Operations Management. Journal of Business Logistics, v. 29, n. 1, p. 31-46, 2008. http:// dx.doi.org/10.1002/j.2158-1592.2008.tb00067.x

MEREDITH, J. Building Operations Management theory through case and field research. Journal of Operations Management, v. 16, n. 4, p. 441-454, 1998.

MIGUEL, P. Metodologia de Pesquisa em Engenharia de Produção e Gestão de Operações: Adoção do estudo de caso na engenharia de produção. Rio de Janeiro: Elsevier, 2010.

MOLLENKOPF, D.; FRANKEL, R.; RUSSO, I. Creating value through returns management: Exploring the marketing-operations interface. Journal of Operations Management, v. 29, n. 1, p. 391-403, 2011. http:// dx.doi.org/10.1016/j.jom.2010.11.004

MOLLENKOPF, D.; GIBSON, A.; OZANNE, L. The integration of Marketing and logistics functions: an empirical examination of New Zealand firms. Journal of Business Logistics, v. 21, n. 2, p. 89-112, 2000.

MORGAN, L. O.; DANIELS, R. L.; KOUVELIS, P. Marketing/manufacturing trade-offs in product line management. IIE Transactions, v. 33, n. 11, p. 949-962, 2001. http://dx.doi. org/10.1080/07408170108936886

MURPHY, P.; POIST, R. Comparative views of logistics and Marketing practitioners regarding interfunctional co-ordination. International Journal of Physical Distribution \& Logistics Management, v. 26, n. 8, p. 15-28, 1996. http://dx.doi. org/10.1108/09600039610128249

O'LEARY-KELLY, S. W.; FLORES, B. E. The integration of manufacturing and marketing/sales decisions: impact on organizational performance. Journal of Operations Management, v. 20, n. 3, p. 221-240, 2002. http:// dx.doi.org/10.1016/S0272-6963(02)00005-0

OLIVA, R.; WATSON, N. Cross-functional alignment in Supply Chain Planning: a case study of sales and operations planning. Journal of Operations Mangement, v. 29, n. 1, p. 434-448, 2011. http://dx.doi. org/10.1016/j.jom.2010.11.012

PAGELL, M. Understanding the factors that enable and inhibit the integration of operations, purchasing and logistics. Journal of Operations Management, v. 22, n. 5, p. 459-487, 2004. http://dx.doi.org/10.1016/j. jom.2004.05.008

PAIVA, E. L. Manufacturing and Marketing integration from a cumulative capabilities perspective. International Journal Production Economics, v. 126, n. 1, p. 379-386, 2010. http://dx.doi.org/10.1016/j. ijpe.2010.04.031 
PARENTE, D. H. Across the manufacturingmarketing interface. International Journal of Operations and Production Management, v. 18 , n. 12 , p. $1205-1222,1998$. http://dx.doi. org/10.1108/01443579810236638

PHILLIPS, L. W. Assessing Measurement Error in Key Informant Reports: A methodological Note on Organizational Analysis in Marketing. Journal of Marketing Research, v. 18, n. 4, p. 395-415, 1981. http://dx.doi.org/10.2307/3151333

PIERCY, N. Framing the problematic relationship between the marketing and operations functions. Journal of Strategic Marketing, v. 15, n. 2-3, p. 185-207, 2007. http://dx.doi.org/10.1080/09652540701319037

PIMENTA, M. Dinâmica de integração interfuncional: um estudo multicaso em marketing e logística. 2011. Tese (Doutorado)-Universidade Federal de São Carlos, São Carlos, 2011.

RHO, B.; HAHM, Y.; YU, Y. Improving interface congruence between manufacturing and Marketing in industrialproduct manufacturers. International Journal of Production Economics, v. 37, n. 1, p. 27-40, 1994. http://dx.doi.org/10.1016/0925-5273(94)90005-1

RINEHART, L.; COOPER, M.; WAGENHEIM, G. Furthering the integration of Marketing and Logistics Through Customer Service in the Channel. Journal of Academy of Marketing Science, v. 17, n. 1, p. 63-71, 1989. http://dx.doi.org/10.1007/BF02726355

ROGERS, D. et al. The returns management process. International Journal of Logistics Management, v. 13, n. 2, p. 1-18, 2002. http://dx.doi. org/10.1108/09574090210806397

SCHOLZ-REITER, B.; FRAZZON, E.; MAKUSCHEWITZ, $\mathrm{T}$. Integrating manufacturing and logistics systems along global supply chains. Journal of Manufacturing Science and Technology, v. 2, n. 1, p. 216-223, 2010. http://dx.doi.org/10.1016/j.cirpj.2010.03.003

SEZEN, B. The role of logistics in linking operations and marketing and influences on business performance. Journal of Enterprise Information Management, v. 18, n. 3 , p. 350-356, 2005. http://dx.doi. org/10.1108/17410390510592012

SHAPIRO, B. P. Can Marketing and Manufacturing Coexist? Harvard Business Review, v. 55, p. 104-114, 1977.

SONG, M.; SWINK, M. Marketing-Manufacturing integration across stages of new product development:
Effects on the Success of High- and Low-Innovativeness Products. IEEE Transactions on Engineering Management, v. 56, n. 1, p. 31-44, 2009. http://dx.doi. org/10.1109/TEM.2008.2009790

SPEH,T. Physical Distribution-Marketing interfaces: Research and managerial implications. In: NATIONAL COUNCIL OF PHYSICAL DISTRIBUTION MANAGEMENT ANNUAL CONFERENCE, 1977. Proceedings... 1977. p. 25-40.

SPRINGINKLEE, M.; WALLENBURG, C.M. Improving Distribution Service Performance through Effective Production and Logistics Integration. Journal of Business Logistics, v. 33, n. 4, p. 309-323, 2012. http://dx.doi. org/10.1111/jbl.12004

ST. JOHN, C. H.; RUE, L. W. Co-Ordinating mechanisms, consensus between Marketing and Manufacturing groups, and marketplace performance. Strategic Management Journal, v. 12, n. 7, p. 549-555, 1991. http://dx.doi. org/10.1002/smj.4250120707

SWINK, M.; SONG, M. Effects of marketing-manufacturing integration on new product development time and competitive advantage. Journal of Operations Management, v. 25, n. 1, p. 203-217, 2007.

THOMÉ, A. M. T. et al. Sales and operations planning: A research synthesis. International Journal of Production Economics, v. 138, p. 1-13, 2012. http:// dx.doi.org/10.1016/j.ijpe.2011.11.027

TURKULAINEN, V.; KETOKIVI, M. Cross-functional integration and performance: what are the real benefits? International Journal of Operations \& Production Management, v. 32, n. 4, p. 447-467, 2012. http:// dx.doi.org/10.1108/01443571211223095

VAN HOEK, R; ELLINGER, A. E.; JOHNSON, M. Great divides: internal alignment between Logistics and peer functions. International Journal of Logistics Management, v. 19, n. 2, p. 110-129, 2008. http:// dx.doi.org/10.1108/09574090810895924

VOORHEES, R. et al. Changes in the Marketing-Logistics relationship. Journal of Business Logistics, v. 9, n. 1, p. 34-50, 1988.

WHYBARK, D. Marketing's influence on Manufacturing practices. International Journal of Production Economics, v. 37, n. 1, p. 41-50, 1994. http://dx.doi. org/10.1016/0925-5273(94)90006-X

YIN, R. Estudo de caso: planejamento e método. 2. ed. Porto Alegre: Bookman, 2001. 
Apêndice 1. Sumário do guia de entrevista.

\section{Abertura}

- Breve apresentação do(s) entrevistador (es) e do entrevistado

- Explicação sobre o contexto da pesquisa e sumarização do processo de entrevista

- Ressalva sobre a confidencialidade das informações gravadas

Dados demográficos

- Título hierárquico e escopo de responsabilidades do entrevistado

- Contextualização do escopo de atuação do entrevistado em relação à estrutura organizacional

- Experiências prévias/ "tempo de casa"

Caracterização dos processos operacionais e pontos de contato

- Descreva os principais pontos de contato entre Marketing, Logística e Produção.

- Como cada uma das funções (Marketing, Logística e Produção) contribui ou impede o bom desempenho da outra? E do todo?

- Que tipo de conflito pode ocorrer entre as funções considerando cada um dos pontos de contato identificados?

Caracterização do nível de integração interfuncional

- Como você avalia o nível de integração entre as funções de Marketing, Logística e Produção (Baixo, Médio ou Alto)?

- Quais critérios caracterizam tal nível de integração?

- Quais ações poderiam incentivar maiores níveis de integração? 
